WOLFLE, DAEL L., The Role of Generalization in Language, British Journal of Psychology, 24 (1933/1934) p.434

\title{
THE RÔLE OF GENERALIZATION IN LANGUAGE.
}

\author{
BY DAEL L. WOLFLE. \\ (From the University of IIississippi.) \\ I. Introduction (pp. 434-6). \\ II. Sound symbolism (pp. 436-8). \\ III. Word meaning (pp. 438-40). \\ IV. Analogic change (pp. 440-3). \\ V. Conclusions (p. 443). \\ References (p. 444).
}

\section{Intronuction.}

THE use of language undoubtedly constitutes one of the most important and most frequent forms of human behaviour. Granting this, it is but natural that both psychologists and linguists have been interested in the interrelations of their sciences on this topic. Psychologists have used certain types of linguistic behaviour as examples of various psychological processes, such as abstraction, generalization, thinking, usually without specific attempts to explain the linguistic behaviour involved. Linguists have perhaps been more interested in psychological explanations of linguistic phenomena than have psychologists, but much of their work seems unsatisfactory from a psychologist's point of view. In this paper I propose to reconsider certain psychological explanations of linguistic processes which have been put forward. Obviously there is no need to explain all linguistic phenomena in terms of a single psychological process. Yet the processes of sound symbolism, word meaning, and analogic change, which have hitherto been treated as isolated phenomena, have a psychological similarity; all three of them are forms of the process of generalization.

Generalization may be defined as the transfer of a response from one situation in which it has been learned, to another in which it has not. The frequency with which this transfer will take place is a function of the similarity of the two stimulating situations. Whether the old response is appropriate in the new situation is irrelevant for our purpose. It is the process of transfer itself which is important. 
Language has usually been defined in terms of the expression of ideas or the communication of thought. The popularity of such a definition can be largely attributed to the fact that language has generally been thought of as a purely human institution. But even so, such a definition is not logically demanded. Moreover, a definition of this kind tends to remove language from experimental investigation; the difficulty of attempting an experimental attack upon idea-expression or thought-communication is manifest. Recent writers have, however, discarded this point of view. De Laguna ((1), pp. 9-19) and Gardiner ((6), pp. $16 \mathrm{ffi}$.) have both substituted more objective definitions.

I propose to define language as a group of behavioural patterns (vocal, gestural, etc.) which, as a result of the community of learning among the users of that language, produce the same response in all of them. How nearly the same the response must be is a practical matter. Absolute identity is, of course, not meant ${ }^{1}$. There is nothing in such a definition which precludes a wink or a blow from being classed as language, provided that all members of a given community have learned to give a common response to these stimuli. The fact that most language is vocal, while of tremendous importance in determining the detailed features of the language, is of absolutely no importance in a discussion of the fundamental nature of language. While the above definition sets no limits to the types of activity which might be classed as language, it does point out the fundamental characteristic of any activity which can be so classified.

A further important characteristic of language is that language develops, changes, and has an existence only as it is used by human beings. Even by competent linguists language has too often been discussed as if it had an existence of its own, had developed of its own accord, and had changed as a result of peculiar characteristics within its own structure, rather than of characteristics of its users. One example will suffice to illustrate this attitude. "Is there not a force," Aiken asks, "corresponding somewhat to inertia in physics, which to a large extent neutralizes and nullifies all the tendencies toward analogic change?" Answering this question in the affirmative, she decides to "recognize a linguistic principle of conservation, defining this as the influence exerted by the language itself to impede and resist change" (1), p. 55). It is of course the habit systems of the language users which resist change. Fortunately a growing recognition of this distinction is now leading many linguists to treat language as a type of human activity rather than

\footnotetext{
1 See the section of this paper on "Word Meaning."
} 
as a self-contained entity. Gardiner in particular has adopted this viewpoint, and the argument of his recent book (6) turns largely upon an examination of a particular example of speech in the concrete setting in which it occurred.

With an objective definition of language as a basis, the purpose of this paper is to define three specific linguistic phenomena (sound symbolism, word meaning, and analogic change) in terms of the more familiar process of generalization. While only three linguistic processes will be analysed here, it seems evident that others will likewise find a similar ultimate explanation. Two of these are the development of linguistic categories (too frequently ascribed to the action of a classificatory instinct) and types of sentence structure or word order.

\section{Sound symbolism.}

It has frequently been asserted that a given sound has a fairly definite and unlearned meaning regardless of the word in which it occurs. For example, Jespersen( $i$ ) discusses in some detail the relations between sound and size, distance, states of mind, and so on. With respect to size Jespersen has pointed out that in many languages there is a significant relation between the particular vowel used and the size denotation of the word. Thus the vowel $i$ (as it is found either in pin or in feet) occurs very frequently in words meant to designate that which is small, weak, insignificant, dainty, or refined; as in little, petit, piccolo, wee, timy (which children often pronounce tecny), slim. The same rowel occurs in the names of small children and small animals, and is frequently used in endearing or depreciative words for children. ('hild (formerly with the ee sound), kid, chit, imp, slip, pigmy, midge are examples of such a usage. The same tendency is found in the names of small objects such as $l i p, p i n$, chink, slit. And lastly, it is found in the diminutive endings of such words as Bobby, baby, anntie, birdie ( (i), p. 402). The use of this vowel in words indicating smallness is not restricted to English. Jespersen quotes examples from Magyar, Latin, Greek, German, Danish, Dutch, Gothic, and Swiss German to illustrate the same usage.

Unlike other exponents of this general thesis, Sapir has experimentally investigated the relation between sound and size. In a study of vowel symbolism he made up lists of pairs of nonsense words differing only in one vowel. These lists were read to groups of subjects who were directed to differentiate between them on the basis of size. "For example, the meaningless words mal and mil were pronounced in that order and given the arbitrary meaning 'table.' The subject decided whether mal. 
seemed to symbolize a large or a small table as contrasted with the word mil" ((9), p. 227). In general Sapir found that the so-called open vowels (those made with a wide opening between tongue and palate) were interpreted as referring to the larger of two objects, and the closed vowels (those made with a narrower opening between tongue and palate) to the smaller. Thus Jespersen's observations were experimentally confirmed. Again, we have such words as large, ocean, vast, grand, and prairie containing open vowels as opposed to the contrasting use of closed vowels illustrated in the previous list. But while it is easier to find examples which confirm Sapir's results than to find contradictory ones, it is not particularly difficult to find words such as big and small in which the vowels are not in agreement with Sapir's results'.

In order to avoid the criticism that Sapir's results might be due to the language habits of the particular subjects used, the experiment should be repeated with subjects of as dissimilar linguistic backgrounds as possible. Sapir's group consisted mainly of high school and college students of American speech habits, although a few native Chinese were included.

The relation between vowel and size meaning might be due to something innate in those who first developed the language, and Sapir is inclined to give an explanation in nativistic terms, saying, "the tendency of symbolisms to constellate in accordance with an unconscious or intuitive logic...is not necessarily based on experience with the stimuli in their normal functional aspects....The influence of specific, functional language factors need not be invoked to explain these symbolisms" ( $(9)$, pp. 238-9). It is, however, as unnecessary to postulate the existence of an innate basis for vowel symbolism as it is to postulate an innate basis, among English-speaking people, for the use of $s$ as a plural sign, or, in another linguistic community, of some other specific instinct for forming plurals. This would necessitate the postulation of different instincts in each different linguistic community; further, it would mean that any particular child would find that language for which it has the proper instincts the one that could be learned with greatest ease. Such reasoning is completely out of step with current psychological theory. But one is not forced to accept the nativistic explanation of this phenomenon for want of a better one. The observed facts fit very nicely into an explana-

\footnotetext{
1 A sample of words having a size reference picked at random (the first word at the top of every other page), from Funk and Wagnell's Practical Standard Dictionary, showed a ratio of about four to one of words confirming to words contradicting the general trend shown in Sapir's study.
} 
tion based on the process of generalization. It is entirely possible that at an earlier stage the language contained more words of the type of big, rista, sea, and immense, as contrasted with small. anel, anger, or tot, dot, and so on. In these lists the names with a large size reference contain closed vowels, while those with a small size reference contain open vowels. If it is true that the language once contained a variety of such words and a variety of vowel-size relations (or what amounts to the same thingno constant relation), then the present condition must have developed by the extension of the particular form which has now become fairly characteristic. But this is nothing more or less than the generalization of a particular relation which has largely supplanted all others. In such a case, as new words were added to the language (whether by borrowing, analogy, or intentional word-building) the rowel meaning would transfer to these new words; or those new words which conform to the already established trends would have the greater survival value. It is, of course, true that the generalization has not been complete, or it would be impossible to find words which contradict the general trend. It is also inpossible to state just why this particular relationship rather than some other was the one which became generalized; but this limitation is characteristic of most explanations.

It must be granted that this explanation of sound symbolism is as purely theoretical and as little experimental as sapir's nativistic one. However, it is more in line with current theory, and has the virtue of greater simplicity. Perhaps the question might be partially answered by contrasting the ease of learning sets of words which did or did not agree with such symbolism. For we might assume that if any innate basis for sound symbolism does exist, it would be easier to learn words which are congruent with this instinctive basis than to learn incongruent words. But it would be necessary to have subjects with no previous language habits. Since the experiment has never been performed, our explanation on the basis of generalization must remain merely a tentative one.

\section{W'ORD MEANING.}

The meaning of any word is in itself an example of generalization. Exactly the same response is never given twice, even by the same individual, to a given word, and ret the similarity of response is sufficiently great to enable us to say that the word has a fairly constant meaning. Bloomfield emphasizes this fact in stating that: "If each experience. owing to its indisputable individuality, were to be accompanied by at special utterance, no sound-sequence would ever be uttered more than 
once, and communication by means of speech would be impossible. It is the habitual inclusion under one form of expression-that is, under one specific sound-sequence-of vast numbers of experiences presenting certain dominant features, which enables us to understand one another" ( $(2)$, p. 83). Gardiner has expressed a similar view in saying "...every word without exception is a class-name; in uttering it the speaker is virtually saying, "Here is a class, and the thing I mean you to understand belongs to that class.' The class is known to the listener by his previous experiences, the word having been applied by others or by himself to many other things falling under the same class" ((B), p. 38).

The first factor determining the limits within which the response to any given word may vary is the nature of the individual's previous experience; in general, the more experience, the less variability. For example, it is hard to predict what responses might not occur among ordinary auditors to the word adiadochokinesis. The variability of response among a group of neurologists would be very much less.

The second factor determining the variability of response to a given word is the proximity of similar or synonymous terms. Contrast, for instance, the generality of a small nose with the specificity of an aquiline nose. The latter term admits of less variability of response because there are more words describing the shape of noses, such as Grecian, Roman, Negroid, straight, hooked, pug, broken, aquiline, than there are words to describe their size, the latter category being almost restricted to small, medium, large, and huge. It is as if each variable, size and shape, included a given amount of territory. The more words there are describing a given variable, the less ground a particular one can cover; the more synonymous or similar terms there are to describe a given object or event, the more restricted the meaning of any one of them will become.

A similar illustration can be given in which form is the less specific variable. Except for the specific square and the less specific Golden Section there are no common names to designate particular types of rectangles. The one name rectangle is consequently very general in meaning and must of necessity cover all shapes and sizes of rectangles. However, the colour of the rectangle can be stated with a comparatively high degree of specificity because of the wealth of colour names. If we talk about a red rectangle we know its colour within a relatively narrow band of wave frequencies, but its actual shape may be almost anything. All that has been specified is that the figure has four right angles. The amount of variability of response to a given linguistic stimulus, together with measures of the interchangeability of two such stimuli, provides an 
objective means for measuring the degree of similarity in the meaning of the two words.

The meaning of any word is ordinarily learned by encountering it in a number of similar situations, abstracting the elements common to these, and then upon this basis generalizing or applying the newly learned word in still other but similar situations. Our ability to learn the meaning of a word in any other fashion is solely due to the fact that language itself may be substituted for other types of activity. The process of learning the meaning of a word is then, ordinarily, one of generalization. Probably more than any other, this linguistic fact has been generally recognized by psychologists. (See for instance Dashiell (3), Chapter $\mathrm{xv}$, or Weiss (12), ('hapter XIII.)

\section{Analogic change.}

Probably the most clear-cut examples of the action of generalization in language are to be found in analogic formations, or, as they have frequently been called, proportional analogies. Such an instance is found in the process by which a child arrives at the form gived from the proportion:

$$
\text { talk: talked : : give: } x
$$

It is not to be understood that such a proportion is ever actually constructed, except as the linguist so constructs it as an illustration. What actually occurs is that the child has learned a great many verbs of the type talk, talked, or want, wanted; when occasion arises for him to use the past tense of a verb of which he knows only the present, the desired form may be obtained by generalization. The other types of analogic effects, which may be classed together under the heading of analogic change, are equally effects of generalization.

Bloomfield defines analogic change as any "change in the form of words [which] is in any sense due to their meaning" ( 2 , p. 221). More commonly, analogic change has been defined as the change in phonetic form of any word due to interference of related or associated words. To illustrate: Latin leris (light) and gravis (heavy) would have become in Italian leve and grave if no influences other than the normal sound changes effective in the development of Italian had been acting. Actually the latter changed to greve, the $a$ of Latin gravis being replaced by an $e$, thus increasing its phonetic similarity with its logical opposite leve. All cases of analogic change are similar to this example in that the change is in the direction of increasing the similarity to some related word or words. It is thus that analogic change is said to be the effect of the interference 
of associated words; which is a more specific way of denoting the meaning relationship.

While meaning provides the essential basis for analogic change, a certain amount of phonetic similarity already existing between the related words is also necessary. Sturtevant writes that any association which is close enough to produce analogic change "must be based upon a certain degree of similarity between the words affected in respect both of meaning and of form. The word mâle could not have changed femelle into 'female' if the words had not already been similar in form" ((10), p. 94).

These are the most important conditions necessary for analogic change. Its effect upon a language is another matter and ordinarily results in increased simplicity. English is a good example of a language in which analogy has simplified the declensions and conjugations and totally removed many former inflectional differences. While English has not yet reached the simplicity of an artificial language such as Esperanto, the trend has been in that direction. Actual attainment of this goal is constantly being checked by such restraining influences as written records; the speech of purists; the fact that complete learning of a given word form tends to prevent any alteration of that form; and the upsetting influence of general sound changes which cut across the lines of analogy and sometimes further alter words previously made similar by the action of analogy.

While both the conditions necessary for analogic changes and the simplifying trend of such changes have been fairly well recognized, explanations of this trend have taken several different forms. One of the most common tendencies has been to explain analogy in terms of purpose. Sometimes these explanations have posited a classificatory or systematizing instinct. Other explanations have made no mention of an instinctive basis but have been as clearly purposive in nature. Even as critical a thinker as Gardiner has fallen into this error, explaining that "analogy has as motive simply the desire for uniformity" (6), p. 140). Vendrys has formulated an equally teleological explanation in writing that "the need of uniformity is satisfied by recourse to analogy" ((11), p. 156).

A second general form of explanation has been based on differences in the ease of pronunciation. Such explanations merely state that a difficult articulation is supplanted by an easy one. The elimination from English of the final sounds of German ach and ich has been explained on such grounds. While linguists do not generally adhere to such theories they crop up nevertheless. Thus Aiken explains all sound change as due 
to the "unconscious urge toward ease in speech" ((1), p. 123). Analogic effects Aiken treats as a special case of this unconscious urge.

Another type of explanation has been offered by some writers, notably Jespersen, in which these changes are attributed to the fact that as a given generation of children learn the language they do not learn it quite as did their parents. A number of generations of such slight differences will quite materially change the language. While Jespersen is undoubtedly correct in noting these differences, there is little evidence that they constitute a complete explanation of analogic change. Wolfle (14) has shown that in an experimental situation children are but little more prone to analogic changes than are adults. Using an artificial language technique(13), a group of children was taught a partially systematic language. Any changes introduced into the language by the children were carefully recorded. These changes were the same as those previously given by a group of adults(13), and occurred with but slightly greater frequency. Even if Jespersen's observation is correct, it still fails to answer the questions of why children do not learn the language as their parents speak it and of why these differences are in the uniform direction of increased simplicity.

The major criticism of all these attempted explanations is that they merely beg the question. This is a common criticism of purposive explanations, and applies here as elsewhere. The wholly unfounded assumption of a peculiar instinct that brings order into linguistic chaos is valueless. And little is gained by altering the purposive explanations to put them on to a non-instinctive level. As for 'ease' theories, they have frequently been criticized on the grounds that anything that is familiar is easy, and that consequently there is no basis in the relative difficulty of different sounds to explain sound change. The German ch is easy for a German, but an Englishman finds it difficult. Russians consider the English $h$ a hard sound, but it gives English-speaking people no trouble. In short, the only criterion of difficulty is whether or not the sound is familiar. Theories based on the abstract ease of articulation of a given sound or sound sequence fail to take this fact into account.

Instead of explaining analogic change on the basis of a purpose, it seems more nearly correct to say that any analogic change is an example of the process of generalization. A form which has been well learned in one, or several, situations is generalized to cover other relatively similar situations. In learning English a child learns that many nouns form their plurals by the addition of $s$. Numerous actual examples are learned before the formal rule is ever encountered. When this plural-forming habit 
is well established it continues to function in new situations. Thus the child may say chocolates without ever having learned or heard that specific plural; the plural foots may be similarly formed. Both of these examples serve to illustrate the extension of a well-established habit that has been built up in countless situations to cover unfamiliar but similar ones. Almost alone among linguists Moore seems to have recognized the importance of generalization in analogy. He writes: "It seems correct to say in general terms that when we make an analogy formation an established speech habit functions unconsciously in a situation which is similar to but not identical with situations in which it has functioned before" ( (8), p. 39). It seems preferable, therefore, to base our explanation of this phenomenon on the established habit systems of the language users rather than on a hypothetical instinct or directing purpose.

\section{Conclusions.}

The linguistic processes of sound symbolism, word meaning, and analogic change have been examined from the point of view of the psychological process of generalization. All three linguistic processes have been shown to be examples of this more fundamental psychological process. In attempting this demonstration it has been claimed that:

(1) The widespread use of a given sound in words with a similar size reference is more probably to be explained on the basis of the spread or generalization of a few words in which such a relation existed, than on the ground of an innate feeling for sound symbolism.

(2) The meaning of any word is a generalization of all the slightly different meanings given to it by the various members of the linguistic community, or by the same member at different times. In order to objectify the problems involved in an examination of this point, meaning has been defined in terms of the responses given to the word when used as a stimulus. Furthermore, the act of learning the meaning of a word is one of generalizing a number of varying situations in which the word has been encountered.

(3) Analogic change in its several different forms has been cited as one of the most obvious examples of the process of generalization, and that explanation has been substituted for purposive and 'ease' theory explanations.

Obviously then a thorough investigation of the psychological character and conditions of generalization is a matter of considerable linguistic importance. 


\section{REFERENCES.}

(1) Alkex, J. L. (1929). Why English sounds change. New York: The Ronald Press.

(2) Bloomfield, L. (1914). An introduction to the study of language. New York: Henry Holt and Co.

(3) Dashield, J. F. (1928). Fundamentals of objective psychology. Boston: Houghton Mifflin and Co.

(4) De Laguxa, G. A. (1927). Speech: its function and developmenl. New Haven, Conn.: Yale Lniversity Press.

(5) Esper, E. A. (1925). “A technique for the experimental investigation of associative interference in artificial linguistic material." Language Monograph No. 1 of the Linguistic Society of America.

(6) Garidner, A. H. (1932). The theory of speech and language. Oxford: The ('larendon Press.

(7) Jespersex, O. (1922). Language: its nature, derelopment, and origin. New York: Henry Holt and Co.

(8) Moone, S. (1925). Historical outline of English phonoloy!l and morphology. Ann Arbor, Mich.: George Wahr. 2nd ed.

(9) SaPIR, E. (1929). "A study in phonetic symbolism." J. Exp. Psychol. xII. 225-39.

(10) Sturtevant, E. H. (1917). Linguistic change. Chicago: Liniversity of Chicago Press.

(11) Vendrys, J. (1925). Language. (Trans. by Paul Radin.) New York: Alfred A. Knopf.

(12) Werss, A. P. (1925). A theoretical basis of human behacior. C'olumbus, Ohio: R. (i. Adams Co.

(13) Wolfle, D. L. (1932). "The relation between linguistic structure and associative interference in artificial linguistic material." Language Monograph No. 11 of the Linguistic Society of America.

(14) - (1931). "A comparison of analogic change in children and adults." Unpublished report at the Toronto meeting of the American Psychological Association.

(Manuscript received 30 Jamurty, 1933.) 